\title{
Study on Buyback Strategy Model of Perishable Products Based on Presale \\ Jie $\mathrm{CHEN}^{1}$, Shi-Yu GUO ${ }^{1, a,{ }^{*}}$
}

\author{
${ }^{1}$ School of Economics and Management, Nanjing University of Science and Technology, \\ Nanjing 210094, China \\ aguoshiyu98@126.com
}

Keywords: Perishable goods, Presale, Buyback, Joint strategy.

\begin{abstract}
The sale processes of perishable goods are divided into two stages (pre-sale stage and spot sale stage) to research the retailers' buyback strategy under uncertain demand conditions. This paper establishes a single pre-sale strategy model and a joint strategy model of pre-sale and buyback, and studies the impact of two models on retailers' decision-making, then analyzes the influence of different parameters on the optimal pre-sale price, the optimal order quantity and the optimal expected profit. The result shows that: the retailers can obtain more profit under the joint strategy when the unit cost of a product is higher or the buyback price is lower or the selling price is higher. At the same time, the optimal pre-sale price of the joint strategy is higher than that of the single strategy, and the optimal order quantity of the joint strategy is smaller than that of the single strategy, the joint strategy can reduce the risk of excess inventory. Based on the result, decision support can be provided for retailers to choose strategies.
\end{abstract}

\section{Introduction}

The perishable goods cannot be stored for a long time due to a seasonal or short life cycle of itself. They also have the 'double short' feature of a short sales period and a short shelf life (2013). The key issue of this study is how to reduce the waste of physical resources and increase the retailers' profits by adopting some marketing strategies. The strategy of pre-sale can not only develop the consumer market, stimulates the potential demand of some consumers, but also can obtain some consumers' demand information in advance (2013). It can be helpful to reduce the uncertainty of the market, and then help retailers to make more reasonable production decisions to reduce the risk of out-of-stock or over-stock.

In order to reduce the unfavorable impact of consumers' uncertain valuations on the retailers, more and more consumers are encouraged to purchase goods in advance, and it can be helpful to provide buyback services based on a pre-sale strategy. When a retailer adopts a buyback strategy, consumers are willing to pay for a product at a higher price than that without a buyback strategy, the reason is that consumers are told that unsatisfactory or unwanted goods can be bought back.

In recent years, many scholars have conducted some researches on the presale or buyback strategies of perishable goods, the breadth and depth of researches have been further increased. Weng\&Parlar (1999) proposed that to attract consumers to buy in advance through discounted pre-sales, and then update the demand for the next stage through the sales volume. The result of the study showed that it can increase total demand and reduce the demand uncertainty by price incentive regulation. McCardle et al. (2004) expanded the single dealer environment and began to study discounted pre-sale strategies in a competitive monopoly environment. Boyaci (2010) proved that the market information can be obtained through pre-sale, then the optimal output can be determined. Zhao et al. (2016) considered an EOQ inventory model with presale policy for deteriorating items, developed the optimal pricing and ordering policy by designing an effective algorithm. Lei et al. (2016) constructed the presale model to get the maximum profit. The results showed that the coordinated operation of dual-channel supply chain network based on presale mode effectively reduced the inventory amount and shortage amount of products simultaneously under certain circumstances. Regarding to the pre-sale issues, at present, the research on the single 
pre-sale strategies is relatively extensive.

With regarding to the research of buyback strategy, many scholars have conducted research in the field of defect-free goods returns. Mostard et al. (2003) studied the existence of defect-free return supply chain under the conditions that expectation and variance of the market demand is known, and obtained the analytical form of the optimal order quantity. Sediri I and Nakade K (2010) studied a buyback contract model of the competitive newsvendor problem between a single supplier and multiple retailers under simultaneous price and safety stock competition. Then optimal wholesale prices for the supplier's and the retailers' profits and supply chain optimal retailers' prices. Nooridaryan M (2015) studied the economic production and inventory model in a three-layer supply chain under buyback strategy. The Stackelberg approach is employed between the members, and the concavity of the profit functions is proved using several theorems. Ji et al. (2017) proved that, in the presence of a buyback promise, the transshipment price has no impact on the manufacturer's incentive to induce retailers to undertake transshipment.

In summary, the current research on the presale strategy or the buyback strategy has been relatively mature, but few studies have combined the presale strategy and the buyback strategy. Based on the review of domestic and international literature on the presale strategy and the buyback strategy, this paper discusses the single presale strategy and the joint strategy of presale and buyback, and compares the two strategies.

\section{Model Description}

Table 1. Symbol Meaning

\begin{tabular}{|c|c|c|c|}
\hline symbol & Meaning & symbol & Meaning \\
\hline C & Unit cost & $N_{2}$ & $\begin{array}{l}\text { The number of consumers who purchase } \\
\text { goods during the spot sale stage which is } \\
\text { a random variable with the expected } \mu_{2} \\
\text { and the variance } \sigma_{2}^{2}\end{array}$ \\
\hline$p$ & $\begin{array}{l}\text { Retail sale price at the spot sale } \\
\text { stage }\end{array}$ & $\rho$ & $\begin{array}{l}\text { The correlation coefficient of the } \\
\text { consumers' arriving number between the } \\
\text { presale and the spot sale stage, } \rho \in[-1,1]\end{array}$ \\
\hline$s$ & $\begin{array}{l}\text { The residual value of unsold goods } \\
\text { at the end of the sale stage }\end{array}$ & $n_{1}$ & $\begin{array}{l}\text { The number of consumers who purchase } \\
\text { the voucher at the end of the pre-sale } \\
\text { stage. }\end{array}$ \\
\hline$b$ & $\begin{array}{l}\text { Unit buyback price of presale } \\
\text { voucher }\end{array}$ & $a$ & Unit presale price \\
\hline$\pi_{i}$ & $\begin{array}{l}\text { The expected profit of the retailer, } \\
i=1,2\end{array}$ & $Q$ & Initial order quantity of the goods \\
\hline$V$ & $\begin{array}{l}\text { The valuation of the goods which is } \\
\text { a random variable with a probability } \\
\text { density of } f(v) \text { and a distribution } \\
\text { function of } F(v)\end{array}$ & $\eta$ & The out-of-stock rate during the sale stage \\
\hline$v$ & $\begin{array}{l}\text { Consumers' real-time valuation } \\
\text { during the spot sale stage }\end{array}$ & $Q_{1}^{*}$ & $\begin{array}{l}\text { The optimal order quantity under the } \\
\text { single strategy }\end{array}$ \\
\hline$N_{1}$ & $\begin{array}{l}\text { The number of pre-ordered } \\
\text { consumers in the pre-sale stage, } \\
\text { which is a random variable with the } \\
\text { expected } \mu_{1} \text { and the variance } \sigma_{1}^{2}\end{array}$ & $Q_{2}^{*}$ & $\begin{array}{l}\text { The optimal order quantity under the joint } \\
\text { strategy }\end{array}$ \\
\hline
\end{tabular}

This article considers a manufacturer, a retailer, and a group of strategic consumers in a two-stage consumption cycle: the presale period and the spot sale period, and mainly study the economic behavior around a kind of perishable goods A. The manufacturing cost of each perishable goods $\mathrm{A}$ 
is $c$, the unit price of the goods in the spot sale period (no discount price period) is $p$, and the unit residual value of the goods which has not been sold at the end of the sale stage is $s$, thus, $s<c<p$. The sale process for retailers is divided into two stages. The first stage is the (pre-sale voucher) pre-sale stage, and the second stage is the (actual goods) spot sale stage. When the retailer only takes the single presale strategy, each presale voucher will be sold at a price $a$ at the presale period. At the spot sale stage, consumers can exchange goods with presale vouchers, and at this time the retailer sells its goods at price $p$.In addition, if the retailer adopts the joint strategy of presale and buyback, each voucher will sold at price $a$ at the presale stage. At the spot sale stage, the retailer can exchange goods for consumers who hold the presale voucher or buyback the voucher at price $b$, at the same time each goods will sold at price $p(0<b<p) . a, p$ and $b$ are all defined at the beginning of the presale stage. There are two decision variables $a$ and $Q$ which belong to the retailer. $Q$ is the order quantity of the retailer, which is determined at the end of the presale stage and before the start of the pre-sale stage. The meaning of each variable in the models is shown in Table 1.

The distribution of $V$ is known to both consumers and the retailer. Assume that the number of the consumers who entering in the market at the pre-sale stage and the spot sale stage are $N_{A}$ and $N_{s}$ respectively, both of them follow the normal distribution. The mean values of them are $\mu_{A}$ and $\mu_{S}$ respectively, and the variances are $\sigma_{A}^{2}$ and $\sigma_{S}^{2}$ respectively. The correlation coefficient between them is $\rho$.

\section{Establishment and Solution of Models}

\section{Single Presale Strategy}

To achieve the greatest expected utility of consumers, strategic consumers will choose to purchase at presale stage or at spot sale stage. The consumers are more likely to choose to purchase the vouchers at the presale period when the value of $p$ is higher. When the presale stage arrives, consumers will compare the utilities of purchasing the voucher with waiting for the spot sale period, and then select the more utility one.

$$
\max \left\{U_{A}, U_{W}\right\}
$$

$U_{A}$ represents the expected utility for a consumer pre-order the voucher at presale stage, and $U_{W}$ represents the expected utility for a consumer choose waiting at presale stage. The valuation $V$ of the goods at the presale stage is uncertain, it is supposed that $V \sim N\left(\mu_{v}, \sigma_{v}^{2}\right)$, the expected utility for a consumer at this stage is shown in Eq.1.

$$
\text { Eq.1 } U_{A}=\int_{a}^{+\infty}(v-a) f(v) d v-\int_{0}^{a}(a-v) f(v) d v=\mu_{v}-a
$$

$v-a$ represents the positive utility of a consumer when $v \geq a . a-v$ represents the loss suffered by a consumer (negative utility) when $v<a$, there is no shortage risk in this stage.

If a consumer chooses to wait at the presale stage, then when the spot sale stage arriving, he can see the physical goods and has a definite valuation $v$ of the goods. When $v \geq p$, he will purchase the physical goods. When $v<p$, if a consumer purchases the goods, he will have a loss, so it is impossible for him to purchase the goods, and the utility will not be negative, but the consumer will face a shortage risk. It is supposed that the stock-out rate at spot sale stage is $\eta$, and then if a consumer chooses to wait for spot-sale period, the expected utility is Eq.2.

$$
\text { Eq. } 2 U_{W}=(1-\eta) \max [(V-p), 0]=(1-\eta) \int_{p}^{+\infty}(v-p) f(v) d v
$$

Only if the expected utility of pre-ordering is not less than that of waiting, and it is not less than 
zero, the consumer will choose to purchase voucher at presale period. That is, $U_{A} \geq U_{W}$ and $U_{A} \geq 0$. At this time, it should meet Eq.3.

$$
\text { Eq. } 3^{\mu_{v}-a \geq(1-\eta) \int_{p}^{+\infty}(v-p) f(v) d v}
$$

In order to encourage consumers to choose to purchase vouchers at presale period and make retailers to obtain the optimal profit, the presale price should meet Eq.4.

$$
\text { Eq. } 4^{a \leq \mu_{v}-(1-\eta) \int_{p}^{+\infty}(v-p) f(v) d v}
$$

The optimal presale price of single pre-sale strategy is set as $a_{1}{ }^{*}$, in order to maximize the profit, $a_{1}^{*}$ should meet Eq.5.

$$
\text { Eq.5 } a_{1}^{*}=\mu_{v}-(1-\eta) \int_{p}^{+\infty}(v-p) f(v) d v
$$

When $U_{A} \geq U_{W}$, consumers will choose to purchase vouchers in the presale stage. The number of consumers who choose pre-order is $N_{A}=N_{1}$, where $N_{1} \sim U\left(\mu_{1}, \sigma_{1}^{2}\right)$. The number of consumers who enter to the market during the spot sale period is $N_{s}$, where $N_{s} \sim U\left(\mu_{s}, \sigma_{s}^{2}\right)$. Consumers will choose to purchase physical goods when $v \geq p$. Due to the out-of-stock risk at this stage, the later-entering consumers may not be able to obtain physical goods, so the proportion of consumers who can actually get physical goods is $(1-\eta)$, the actual number of consumers who can actually get physical goods is $N_{2}=(1-\eta) N_{S}$, where $N_{2} \sim U\left(\mu_{2}, \sigma_{2}^{2}\right)$, so $\mu_{2}=(1-\rho)(1-\eta) \mu_{s}, \sigma_{2}=(1-\eta) \sigma_{s} \sqrt{1-\rho^{2}}$.

At the end of the presale stage, the retailer can get the actual number $\boldsymbol{n}_{1}$ of vouchers sold.

The total expected profit of the retailer is $\pi_{1}$, Eq.6.

$$
\text { Eq.6 } \pi_{1}=E\left\{a n_{1}+p \min \left\{Q-n_{1}, N_{2}\right\}+s \max \left\{Q-n_{1}-N_{2}, 0\right\}-c Q\right\}
$$

The optimal order quantity according to the Newsboy Model is $Q_{1}^{*}$, Eq.7.

$$
\text { Eq.7 } Q_{1}^{*}=k \sigma_{2}+\mu_{2}+n_{1}=k(1-\eta) \sigma_{s} \sqrt{1-\rho^{2}}+(1-\rho)(1-\eta) \mu_{s}+n_{1}
$$

The optimal total expected profit is $\pi_{1}^{*}$, Eq.8.

$$
\begin{aligned}
\pi_{1}^{*}= & \left(a_{1}^{*}-c\right) \mu_{1}+(p-c) \mu_{2}-(p-s) \phi(k) \sigma_{2} \\
= & \left(a_{1}^{*}-c\right) \mu_{1}+(p-c)(1-\rho)(1-\eta) \mu_{s}- \\
\text { Eq.8 } \quad & (p-c) \phi(k)(1-\eta) \sigma_{s} \sqrt{1-\rho^{2}}
\end{aligned}
$$

Where $k=\varphi^{-1}\left(\frac{p-c}{p-s}\right), \varphi(\cdot)$ and $\phi(\cdot)$ are the distribution function and probability density function of the standard normal distribution, respectively.

\section{Joint Strategy of Presale and Buyback}

The difference between the joint strategy and the single presale strategy is that at the spot-sale stage, the retailer promised that consumers who have purchased vouchers can choose to exchange goods or return the vouchers at price $b$.

At the beginning of the spot sale period, it is a common reason that consumers will choose to return the vouchers if the product doesn't meet their expectations. Under the buyback policy, if a consumer returns the voucher, then the utility is $b-a$, and the loss is $a-b$.If someone exchanges a physical goods with his voucher, the utility is $v-a$. When the utility of exchanging goods less than the utility of returning voucher, that is, $v-a<b-a$,consumers will choose to return the voucher, so 
the condition of return the voucher is $v<b$.

The expected utility for a consumer to choose to pre-order at the presale stage is $U_{A}$, Eq.9.

$$
\text { Eq.9 } U_{A}=\int_{b}^{+\infty}(v-a) f(v) d v+\int_{0}^{b}(b-a) f(v) d v=\int_{b}^{+\infty} v f(v) d v+\int_{0}^{b} b f(v) d v-a
$$

The expected utility for a consumer to choose to wait for spot sale period is $U_{W}$, Eq.10.

$$
\text { Eq.10 } U_{W}=(1-\eta) \max [(V-p), 0]=(1-\eta) \int_{p}^{+\infty}(v-p) f(v) d v
$$

If $U_{A} \geq U_{W}$, the consumer will choose to pre-order. That is, Eq.11.

$$
\text { Eq.11 } a \leq \int_{b}^{+\infty} v f(v) d v+\int_{0}^{b} b f(v) d v-(1-\eta) \int_{p}^{+\infty}(v-p) f(v) d v
$$

In order to maximize the profit, the optimal pre-sale price of the joint strategy is $a_{2}^{*}$, Eq.12.

$$
\text { Eq. } 12 a_{2}^{*}=\int_{b}^{+\infty} v f(v) d v+\int_{0}^{b} b f(v) d v-(1-\eta) \int_{p}^{+\infty}(v-p) f(v) d v
$$

In order to encourage consumers to choose to pre-order, the retailer need to adopt a pre-sale price that is lower than the spot price, that is, $a_{2}^{*}<p$.

Theorem 1If the joint strategy is adopted, the optimal pre-sale price set by the retailer should be higher than the optimal pre-sale price under the single strategy.

Proof:

$$
\begin{aligned}
a_{1}^{*}-a_{2}^{*} & =\mu_{v}-\int_{b}^{+\infty} v f(v) d v-\int_{0}^{b} f(v) d v \\
\text { Eq.13 } \quad & =\int_{0}^{b}(v-b) f(v) d v<0
\end{aligned}
$$

So $a_{1}^{*}<a_{2}^{*}$,Theorem 1 is proved.

If $v<b$, the pre-ordered consumers will choose to return their vouchers, and the proportion of that is $F(b)$,combined with the single strategy model, the real number of the consumers who return vouchers is $n_{1} F(b)$.

The total expected profit under the joint strategy of pre-sale and buyback is $\pi_{2}$, Eq.14.

$$
\text { Eq. } 14 \pi_{2}=E\left\{a n_{1}+p \min \left\{Q-n_{1} F(b), N_{2}\right\}+s \max \left\{Q-n_{1} F(b)-N_{2}, 0\right\}-c Q-b n_{1} F(b)\right\}
$$

The optimal order quantity according to the Newsboy Model is $Q_{2}^{*}$, Eq.15.

$$
\text { Eq. } 15 Q_{2}^{*}=k(1-\eta) \sigma_{s} \sqrt{1-\rho^{2}}+(1-\rho)(1-\eta) \mu_{s}+n_{1} \bar{F}(b)
$$

The optimal total expected profit is $\pi_{2}^{*}$, Eq.16.

$$
\begin{aligned}
& \qquad \pi_{2}^{*}=a_{2}^{*} \mu_{1}+(p-c)(1-\rho)(1-\eta) \mu_{s}-(p-s) \phi(k)(1-\eta) \sqrt{1-\rho^{2}} \sigma_{s} \\
& \text { Eq.16 } \quad-b \mu_{1} F(b)-c \mu_{1} \bar{F}(b)
\end{aligned}
$$

\section{Numerical Analysis}

To verify the validity of the proposed models above, moon cake gift box B produced by a retailer is taken as an example, perform numerical analysis. In order to make the experiment more credible, 
we take a set of parameter values in both models, the parameter values are shown in Table 2 .

Table 2. Parameter Values

\begin{tabular}{|l|l|l|l|l|l|l|l|l|l|}
\hline$p(\$)$ & $c(\$)$ & $s(\$)$ & $b(\$)$ & $\rho$ & $\mu_{1}(\$)$ & $\mu_{s}(\$)$ & $\sigma_{1}$ & $\sigma_{s}$ & $\eta$ \\
\hline 200 & 95 & 25 & 170 & 0.4 & 100 & 100 & 5 & 5 & 0.9 \\
\hline
\end{tabular}

The consumers' valuations for goods are uniformly distributed, $V \sim U\left(\mu_{v}, \sigma_{v}^{2}\right)$, where $\mu_{v}=190, \sigma_{v}=20$.

With other parameter values remaining unchanged, let $c$ gradually changes from 25 to 295.The optimal total expected profits of the two strategies are shown in Figure 1.It can be seen from the figure that the single strategy is more attractive to retailers when the cost is lower. But with the increase of $c$, the profit of the joint strategy exceeds that of the single pre-sale strategy gradually, at this time, the joint strategy is more attractive to retailers.

With other parameter values remaining unchanged, let $p$ gradually changes from 50 to 250. The optimal total expected profits of the two strategies are shown in Figure 2. As we can see, there is a critical value for the spot sale price $\bar{p}$, when $p<\bar{p}$, the single strategy is more attractive for retailers. When $p>\bar{p}$, the joint strategy is more attractive to retailers.

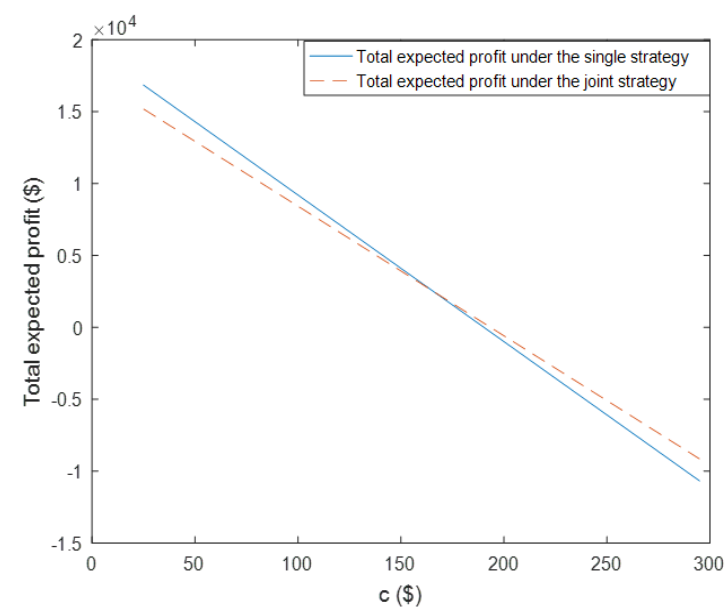

Fig.1. Total profits change with $c$

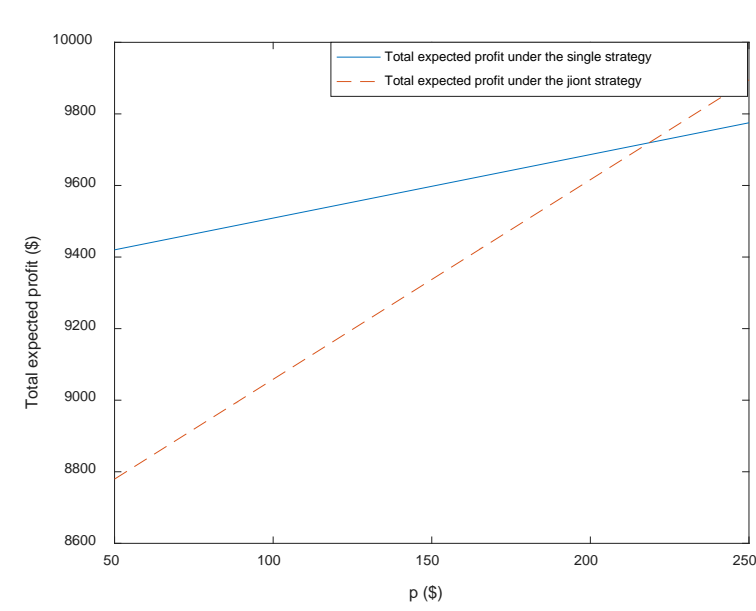

Fig. 2. Total profits change with $p$

With other parameter values remaining unchanged, let $b$ gradually changes from 75 to 200.The profits of the two strategies are shown in Figure 3.It can be clearly seen that, there is a critical value for the buyback price $\bar{b}$. When $b<\bar{b}$, the profit of the joint strategy is more attractive for retailers. When $b>\bar{b}$, the single strategy is more attractive for retailers. The reason is that, the increase of $b$ will increase consumers' expected utility of pre-order and reduce the order quantity of retailers. At the same time, it will increase the number of consumers who will return the vouchers, thus increase the buyback costs.

With other parameter values remaining unchanged, let $\rho$ gradually changes from 0.1 to 0.9 . The optimal quantities of the two strategies are shown in Figure 4. The profits and the optimal order quantities of the two strategies are shown in Table 3. As we can see, there is a critical value for $\bar{\rho}$. When $\rho>\bar{\rho}$, the joint strategy is more attractive to retailers. At the same time, the optimal order quantity under the joint strategy is less than that under the single strategy, the joint strategy can reduce the risk of excess inventory. 




Fig. 3. Total profits change with $b$

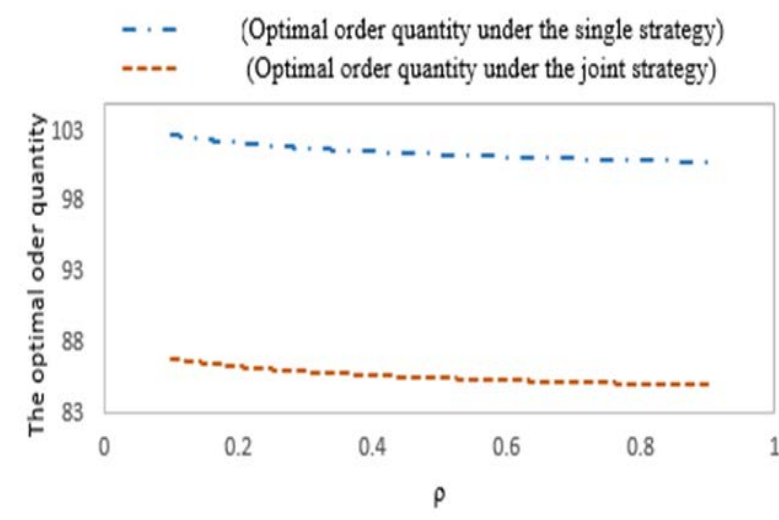

Fig 4. Optimal order quantities change with $\rho$

Table 3 The optimal profits and order quantities

\begin{tabular}{|l|l|l|l|l|}
\hline$\rho$ & $\pi_{1}^{*}(1000 \$)$ & $\pi_{2}^{*}(1000 \$)$ & $Q_{1}^{*}$ & $Q_{2}^{*}$ \\
\hline 0.1 & 9.97 & 9.13 & 102 & 87 \\
\hline 0.2 & 9.87 & 9.23 & 102 & 86 \\
\hline 0.3 & 9.80 & 9.30 & 102 & 86 \\
\hline 0.4 & 9.75 & 9.41 & 102 & 86 \\
\hline 0.5 & 9.69 & 9.49 & 102 & 86 \\
\hline 0.6 & 9.66 & 9.56 & 101 & 85 \\
\hline 0.7 & 9.59 & 9.68 & 101 & 85 \\
\hline 0.8 & 9.53 & 9.80 & 101 & 85 \\
\hline 0.9 & 9.50 & 9.92 & 101 & 85 \\
\hline
\end{tabular}

\section{Conclusion}

This paper applies presale and buyback strategies to perishable goods. Taking the maximize profit of retailers as a primary purpose, this paper studies the impact of two models on retailers' decision-making. The sale process is divided into two stages: presale stage and spot sale stage. Established a single pre-sale strategy model and a joint strategy of pre-sale and buyback model, and analyzed the influence of different parameters on the optimal pre-sale price, the optimal order quantity and the optimal expected profit. Then through comparative analysis, it is concluded that when the unit cost is higher or the buyback price is lower or the selling price is higher, the retailers are more suitable to adopt the joint strategy. The study also found that, under the joint strategy, the pre-sale price set by the retailers is higher, and the overflow price of this part is equivalent to the cost paid by the consumers to reduce the pre-order risk. At the same time, the optimal order quantity under the joint strategy is less than that under the single strategy, the joint strategy can reduce the risk of excess inventory. This paper assumes that consumers are homogenous. In actual situations, each person has different valuation distributions of goods due to factors such as his own experience and demand. Therefore, we may consider studying heterogeneous consumers in the future. In addition, this paper is aimed at a monopoly retailer to conduct research, but as we all know, the market is competitive, so in the future, it is better for research if considering the situation in which that multiple retailers compete with each other.

\section{References}

[1] Weng Z K, MAHMUTPARLAR. Integrating early sales with production decisions: analysis and insights[J]. Iie Transactions, 1999, 31(11):1051-1060.

[2] Mccardle K, Rajaram K, Tang C S. Advance Booking Discount Programs Under Retail 
Competition[J]. Management Science, 2004, 50(5):701-708.

[3] Zeng C. Optimal Advance Selling Strategy under Price Commitment[J]. Pacific Economic Review, 2013, 18(2):233-258.

[4] Chen J, Grewal R. Competing in a supply chain via full-refund and no-refund customer returns policies[J]. International Journal of Production Economics, 2013, 146(1):246-258.

[5] Mostard J, Teunter R. The Newsboy Problem with Resalable Returns[J]. Econometric Institute Research Papers, 2003, 169(1):81-96.

[6] Jian L I, Bo W, Hao S, et al. Manufacturer's buy-back policy in two-stage e-commerce supply chain with customer return policy[J]. Computer Integrated Manufacturing Systems, 2015, 21(4):1089-1100.

[7] Li C, Zhang F. Advance Demand Information, Price Discrimination, and Pre-Order Strategies[J]. Manufacturing \& Service Operations Management, 2013, 15(1):57-71.

[8] Wen H, Cao X, Li J. Research on buy-back policy optimization and coordination of closed-loop supply chain based on CVaR[J]. Journal of Systems Engineering, 2013, 28(2):211-217.

[9] Chew E P, Lee C, Liu R, et al. Optimal dynamic pricing and ordering decisions for perishable products[J]. International Journal of Production Economics, 2014, 157(1):39-48.

[10]Önal M. The two-level economic lot sizing problem with perishable items[J]. Operations Research Letters, 2016, 44(3):403-408.

[11] Xu X, Li X, Bian Y, et al. ADVANCE SELLING IN THE PRESENCE OF PRODUCT DIFFUSION EFFECT[J]. Journal of Systems Science and Systems Engineering (English), 2017, 26(1):77-99.

[12]Boyaci T, ÖzalpÖzer. Information Acquisition for Capacity Planning via Pricing and Advance Selling: When to Stop and Act?[J]. Operations Research, 2010, 58(5):1328-1349.

[13]Zhao L, You J. Optimal Pricing and Ordering Policy for Deteriorating Items with Stock-and-Price Dependent Demand and Presale Rebate[M]. Hindawi Publishing Corp. 2016.

[14]Lei Z, Yang C. Collaborative optimization of apparel dual-channel supply chain network based on presale mode[J]. Computer Integrated Manufacturing Systems, 2016, 22:220-231.

[15]Ji X, Sun J, Wang Z. Turn bad into good: Using transshipment-before-buyback for disruptions of stochastic demand [J]. International Journal of Production Economics, 2017, 185:150-161.

[16] Sediri I, Nakade K. Competition in a Decentralized Supply Chain under Price and Safety Stock Sensitive Stochastic Demand and Buyback Contract[J]. Jamdsm, 2010, 4(3):627-636.

[17]Nooridaryan M. Pricing and ordering decisions in a supply chain with imperfect quality items and inspection under buyback of defective items[J]. International Journal of Production Research, 2015, 53(15):4553-4582. 